\title{
COMPARISON BETWEEN POSTERIOR LUMBAR FUSION WITH PEDICLE SCREWS AND POSTERIOR LUMBAR INTERBODY FUSION WITH PEDICLE SCREWS IN ADULT SPONDYLOLISTHESIS
}

\author{
Fernando Luiz Rolemberg Dantas', Mirto Nelso Prandini', Mauro A.T. Ferreira ${ }^{3}$
}

\begin{abstract}
The purpose of this study was to compare patients with lumbar spondylolisthesis submitted to two different surgical approaches, and evaluate the results and outcomes in both groups. In a two-year period, 60 adult patients with lumbar spondylolisthesis, both isthmic and degenerative, were submitted to surgery at the Biocor Institute, Brazil. All patients were operated on by the same surgeon (FLRD) in a single institution, and the results were analyzed prospectively. Group I comprised the first 30 consecutive patients that were submitted to a posterior lumbar spinal fusion with pedicle screws (PLF). Group II comprised the last 30 consecutive patients submitted to a posterior lumbar interbody fusion procedure (PLIF) with pedicle screws. All patients underwent foraminotomy for nerve root decompression. Clinical evaluation was carried out using the Prolo Economic and Functional Scale and the Rolland-Morris and the Oswestry questionnaire. Mean age was 52.4 for Group I (PLF), and 47.6 for Group II (PLIF). The mean follow-up was 3.2 years. Both surgical procedures were effective. The PLIF with pedicle screws group presented better clinical outcomes. Group I presented more complications when compared with Group II. Group II presented better results as indicated in the Prolo Economic and Functional Scale.
\end{abstract}

KEY WORDS: posterior lumbar interbody fusion (PLIF), posterior lumbar fusion, spondylolisthesis, pedicle screws, lumbar spine, spinal instrumentation.

Estudo comparativo entre fusão lombar posterior com parafuso pedicular e fusão intersomática lombar posterior associada com parafuso pedicular em espondilolistese no adulto

\begin{abstract}
RESUMO - O objetivo foi comparar dois grupos de pacientes portadores de espondilolistese lombar que foram submetidos a dois procedimentos cirúrgicos distintos, avaliando os resultados clínicos levando em consideração a qualidade de vida. Durante o período de 1998 a 2001 sessenta pacientes portadores de espondilolistese da coluna lombar ístmica e degenerativa foram submetidos a tratamento cirúrgico no Hospital Biocor em Belo Horizonte, por um mesmo cirurgião foram analisados prospectivamente. Os primeiros trinta pacientes foram submetidos a fusão posterior com parafusos pediculares e os trinta seguintes a fusão posterior com parafusos pediculares associada a fusão intersomática posterior. Os pacientes foram submetidos a liberação radicular com laminectomia e foraminotomia. A avaliação clínica foi feita utilizando as escalas de Prolo Econômico e Funcional, o questionário de Rolland-Morris e de Oswestry. Os resultados clínicos apresentaram que os dois procedimentos realizados foram eficazes. Houve maior número de complicações relacionadas com a biomecânica no grupo que foi submetido somente à fusão posterior e o grupo submetido à fusão posterior associada a fusão intersomática apresentou melhores resultados com retorno as atividades diárias e melhora da qualidade de vida.
\end{abstract}

PALAVRAS-CHAVE: fusão intersomática lombar posterior, fusão lombar posterior, espondilolistese, fixação pedicular, coluna lombar, instrumentação vertebral.

Spondylolisthesis is the subluxation of a vertebral body over another in the sagittal plane. It represents a particular and relatively frequent mechanism of intervertebral instability. The first case of lumbosacral spondylolisthesis was described by Herbinaux in 1772, an obstetric surgeon that described a bony prominence, anterior to the sacrum and caused pelvic outlet narrowing, due to a forward slip of $L 5$ on the sacrum ${ }^{1}$, causing a difficult delivery. This pathology can be caused by ligamentous laxity, a defect in

\footnotetext{
${ }^{1}$ Médico Neurocirurgião do Hospital Biocor, Belo Horizonte MG, Brasil, Pós-Graduando de Neurocirurgia da Universidade Federal de São Paulo, Escola Paulista de Medicina (UNIFESP); ${ }^{2}$ Professor Adjunto de Neurocirurgia da UNIFESP, São Paulo SP, Brasil; ${ }^{3}$ Neurocirurgião do Hospital Madre Tereza, Belo Horizonte MG, Brasil.
}

Received 8 February 2007, received in final form 11 May 2007. Accepted 22 June 2007. 
the pars interarticularis, previous surgery, or may be traumatic. It occurs in up to $5 \%$ of the general population and affects all ages ${ }^{2}$. The surgical treatment of spondylolisthesis is indicated for cases of neurogenic claudication, intractable radicular pain, severe low-back pain, presence of neurological symptoms, failure of conservative management, radiological instability, progressive worsening of the listheses, Meyerding grade III and IV listheses, and spondylopto$\mathrm{sis}^{3-5}$. The ideal surgical treatment remains controversial ${ }^{6-8}$.

The procedure to use pedicle screws in the treatment of lumbar spondylolisthesis was popularized in Europe by Roy-Camille in $1970^{5}$. Briggs and Milligan used the posterior intersomatic fusion with autologous bone in the discal space ${ }^{9}$. This procedure was popularized by Cloward in $1953^{10}$. Steffe ${ }^{11}$ was the first to propose the association of intersomatic lumbar fusion and intersomatic spacers and decompression with fusion using pedicle screws. Suk ${ }^{12}$ used bone grafts as intersomatic spacers and pedicular fixation in the treatment of isthmic spondylolisthesis, to provide a truly circumferencial fusion with good results. Due to the complications of the collapsing of the impacted bone grafts into the disc space, we have used other materials as intersomatic spacers including carbon fiber as proposed by Brantingan ${ }^{13}$, titanium as proposed by Ray ${ }^{14}$, and titanium blocks coated with plasmapore as proposed by La Rosa ${ }^{15}$.

We have found few papers in the literature comparing the use of pedicle screws with pedicle screws associated with a posterior intersomatic posterior fusion in the surgical management of lumbar spondylolisthesis ${ }^{11,12,15,16}$. The purpose of this study was twofold: to compare efficacy of the posterior lumbar interdody fusion (PLIF) with the posterior lumbar fusion (PLF); and to compare the complications of both procedures.

\section{METHOD}

We have prospectively studied 60 patients with lumbar spondylolisthesis, between August 1999, and August 2001. The patients were operated on by one surgeon (F.L.R.D.) in a single institution, using two different techniques with a minimum follow-up of two years. Patients were divided into two groups. Group I comprised the first 30 consecutive patients of the series submitted to a posterior fixation with pedicle screws (PLF). Group II comprised the last 30 patients submitted to a posterior lumbar interbody fusion procedure (PLIF).

Socon and Spine System (Aesculap, Tuttingham, Germany) pedicle screws were used in both groups, and the Prospace (Aesculap, Tuttingham, Germany) titanium plasmapore-coated spacers were used in the PLIF group.
The inclusion criteria were: no past history of spine surgery for spondylolisthesis; age between 18 and 65; failure of maximum conservative management (including intensive physical therapy) for at least 6 months. Exclusion criteria were infection and generalized bone disease.

All patients have signed an informed consent term and the study was approved the Ethics Committee of the Biocor Institute.In this series, 33 patients were female (55.5\%) and 27 were male (45.5\%). Seventeen males and 13 females comprised Group I (PLF). In Group II (PLIF), there were 20 females and 10 males. Mean age in Group I was 52.4 y/o, and in Group II it was 47.6 y/o. The overall age distribution was: 13 patients $(21.6 \%)$ between age $30-39 ; 14$ patients $(23.3 \%)$ between age $40-49$; and 17 patients (28.3\%) between age 50-59. Sixteen patients (26.6\%) had age between 60-65.

Twenty-seven patients had spondylolisthesis at L4-5 level and another 27 at L5-S1 level. It affected the L4-L5-S1 levels in 5 cases, and the L3-4 level was abnormal in one case. In Group I (PLF) the disease affected the L4-5 level in 15 cases, the L5-S1 level in 12 cases, the levels L4-L5-S1 in one case, and the level L3-L4 in one case. In the overall series 51 $(85 \%)$ patients were submitted to lumbar fusion in one level, and $9(15 \%)$ patients required a two-level fixation procedure. In Group I (PLF), 27 (90\%) patients required 1 level fixation, and $3(10 \%)$ patients required fixation in two levels. Twenty-four patients submitted to the PLIF procedure $(80 \%)$ were fixated in one level while six $(20 \%)$ required a two-level fixation.

There were 46 cases of degenerative spondylolisthesis $(76.6 \%)$ and 14 cases of isthmic spondylolisthesis (24.4\%). Group I had a higher incidence of the degenerative type in relation to the isthmic, 26 and 4 patients, respectively. Group II presented similar characteristics with 20 cases of the degenerative type and 10 cases of the isthmic type. Spondylolisthesis was classified as grade I in 31 cases $(51.6 \%)$; grade II in 27 cases (45\%); and grade III in 2 cases $(2.3 \%)$. The distribution of the disease in both groups were: PLF Group, 16 cases grade I, 13 cases grade II, and 1 case grade III. In the PLIF Group there were 15 cases grade I, 14 cases grade II, and 1 grade III.

Clinical symptoms and signs included low-back pain in 58 cases $(96.6 \%)$, radicular pain in 56 patients $(93.3 \%)$, neurogenic claudication in 30 patients $(50 \%)$ and neurological deficits were observed in 24 cases (40\%). Comparison of symptoms and signs in Groups I and II showed: low-back pain in 28 cases $(93.3 \%)$ in Group I, and in 30 cases (100\%) in Group II; neurogenic claudication in 19 (63.3\%) in Group I, and in $11(36.6 \%)$ in Group II; neurological deficit in 14 patients $(46.6 \%)$ of Group I, and in 10 patients $(33.3 \%)$ of Group II. The neurological deficits consisted of motor weakness in 2 patients $(6.6 \%)$ in Group I, and in 3 patients (10\%) in Group II. Hypesthesia was found in 12 patients (40\%) in Group I, and in 7 patients (23.3) in Group II.

The radiological pre-operative evaluation included static and functional lumbar spine plain X-rays; computed tomography $(\mathrm{CT})$ scans; and magnetic resonance imaging (MRI) scans. The anatomical features including the bony anatomy, the aspect of the disc, the neural elements, and the grade of the listheses were carefully evaluated for proper surgi- 
cal planning. All patients were treated conservatively for at least 6 months. Treatment included analgesics and physical therapy. Surgical indications were: neurogenic claudication, severe low-back pain; radiculopathy refractory to clinical treatment; and motor deficit. Foraminotomy and discectomy were performed in all cases. No bracing was used in the post-operative period. Patients were encouraged to ambulate in the first post-operative day.

Patient data analysed were: age; sex; clinical presentation, type and degree of spondylolisthesis. Co-morbidities like diabetes mellitus, obesity, and smoking were found in both groups, but no significant statistical difference was found between the two groups. The degree of spondylolisthesis was determined according to the Meyeding classification $^{3}$ and its type according to the Newman system ${ }^{17}$. Patients were clinically evaluated with the Prolo Economic and Functional Scale ${ }^{18}$ and with the Rolland-Morris ${ }^{19}$ and Oswestry ${ }^{20}$ questionnaires, filled by the patient pre-oper-

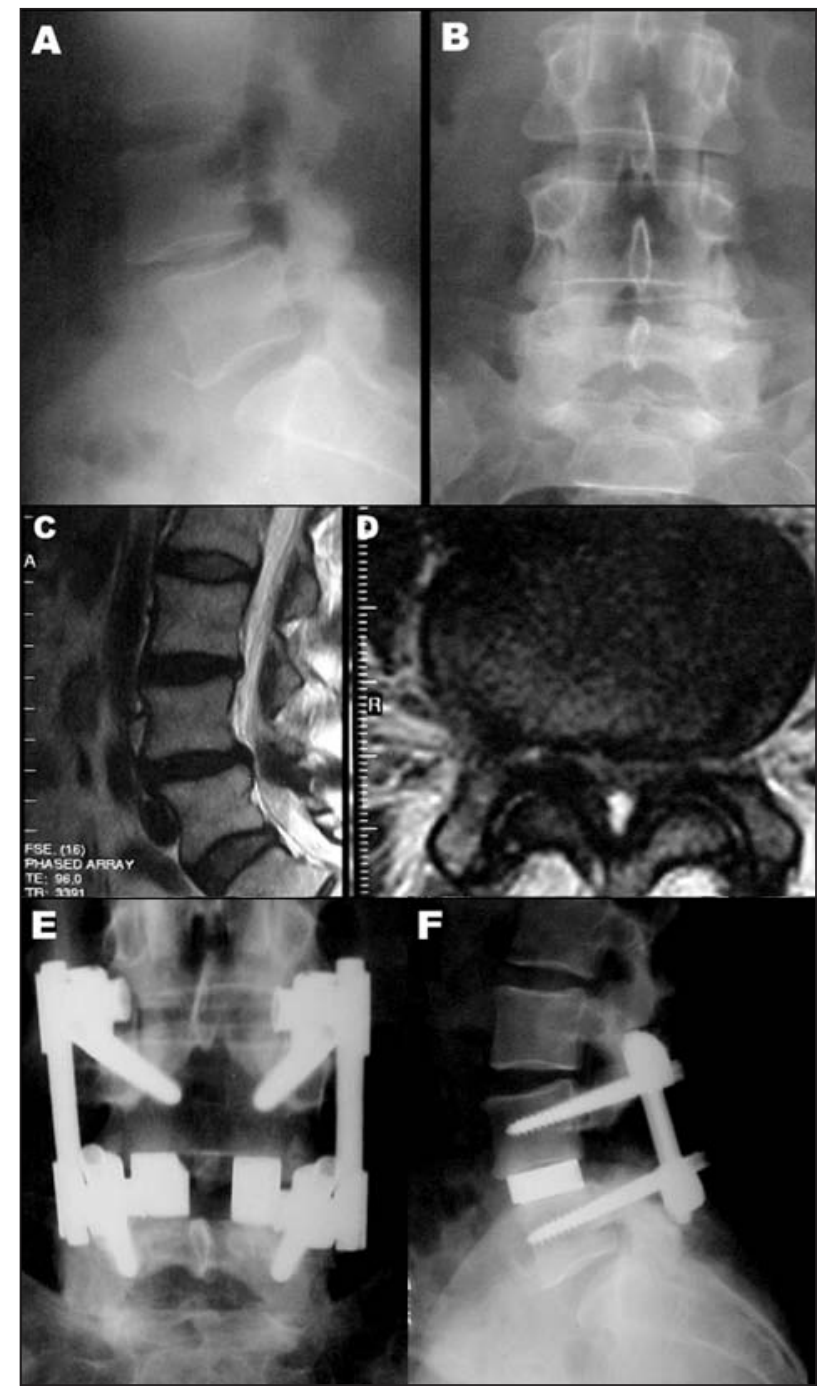

Fig 1. (A) Anterior-posterior and (B) lateral radiographs of a patient with an degenerative spondylolisthesis L4-L5 grade I. (C) and (D) MRI coronal and axial. (E) and (F) The anterior-posterior and lateral radiographs at 2-year pós-operatoire. atively and in up to two-years post-operatively. Post-operative radiological control included simple lumbar X-rays, both AP and lateral views, performed immediately post-operatively, and in 30 days, 3 months, 6 months, and in one and two years in order to assess correct hardware placement, and lumbar spine stability.

Clinical results were studied prospectively. Group I and II outcomes were evaluated with the Prolo, Oswestry, and Rolland-Morris scales pre-operatively and 2 years post-operatively. Statistical analysis was performed using the MannWhitney U-test, Bartlett's test, and the Pearson qui-square and Fisher tests. The 0.05 value was used to define statistical significance.

Surgical technique - Patients were carefully positioned in the prone position. Thoracic and abdominal compression were avoided by proper padding. All patients were submitted to a posterior approach with a midline incision and dissection, exposing the spinous processes, laminae, and the bilateral facets. A postero-lateral decompression of the neural elements was then performed with laminectomy, medial facetectomy, and foraminotomy. Total disc resection was performed with preservation of both vertebral plateau. After the discectomy and bilateral foraminotomy, and with the use of the C-arm, 7 to $11 \mathrm{~mm}$ intersomatic distractors are placed in the discal space. The titanium plasmapore-coated intersomatic spacers are impacted bilaterally, advanced to the mid-portion, but no passing the anterior rim of the vertebral body, and their size matches the size of the distractors. The spacers are $7 \mathrm{~mm}, 9 \mathrm{~mm}$, and $11 \mathrm{~mm}$ high; and $22 \mathrm{~mm}, 24 \mathrm{~mm}$, and $26 \mathrm{~mm}$ wide. Lumbar spine screws are 6.0 or $6.5 \mathrm{~mm}$ wide and 40 to $50 \mathrm{~mm}$ long.

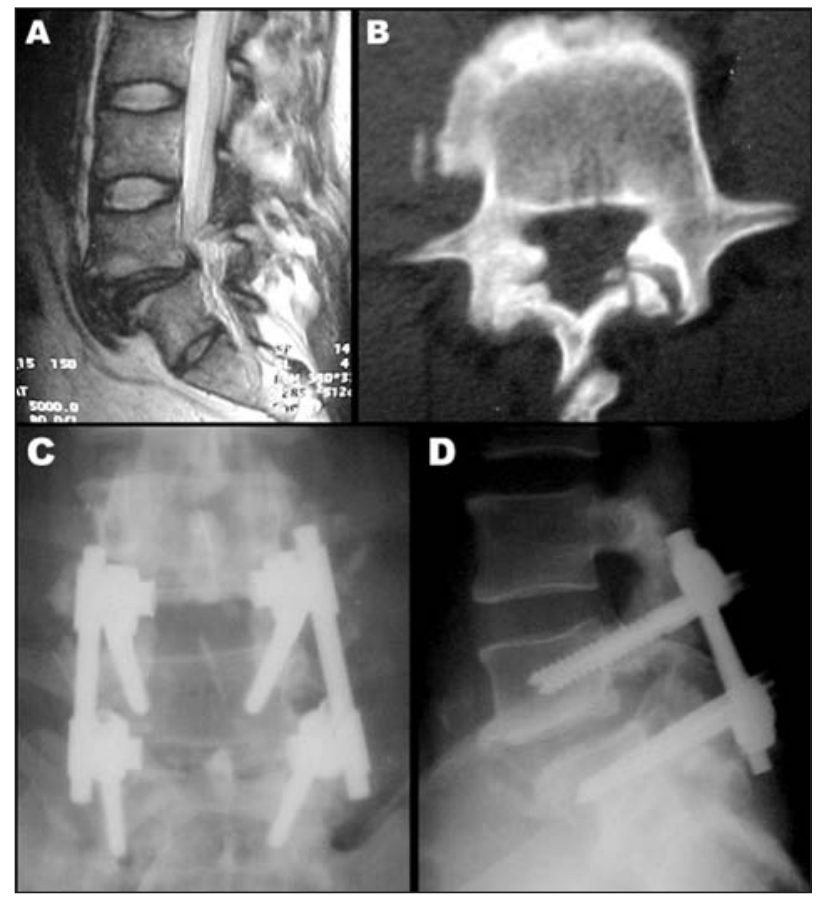

Fig 2. (A) RMI and (B) CT of a patient with a degenerative spondylolisthesis L5-S1 grade I. (C) and (D) the anterior-posterior and lateral radiographs at 2-year pós-operatoire. 
Sacral screws are 6.5 and $7.0 \mathrm{~mm}$ wide and $40 \mathrm{~mm}$ long. The fixation procedure included only the affected segment of the spine, and reduction of the listheses at this point is always attempted. The lateral rods are placed into position and curved along the angle of the lumbar or lumbosacral spine. After facet scarification bone grafts are placed to promote fusion (Fig 1) Surgical technique in Group I was the same as described above, except for the placement of spacers (Fig 2).

\section{RESULTS}

Group I (PLF) - The median Economic Prolo scale score pre-operatively was 2.4 (1-4) and post-operatively $3.2(2-5)$. Thirteen patients $(43 \%)$ returned to their baseline normal activities (Prolo grades 4 and 5). Five patients (16\%) improved, but could not resume all their normal activities (Prolo grade 3 ). Twelve patients $(41 \%)$ did not return to their normal activities (Prolo grades 1 and 2). The pre-operative median Functional scale was 2.3 (1-5); post-operative 3.6 (2-5). Eighteen patients (60\%) reported significant functional improvement, with no or sporadic back pain (Prolo 4 and 5). Partial functional recovery was observed in 10 patients (33.3\%), with back pain and residual pain in the lower extremities (Prolo grade 3). Two patients (6.6\%) had no improvement (Prolo 1 and 2). Thirteen patients (43\%) resumed their normal activities post-operatively (Prolo 4 and 5); 5 patients $(16 \%)$ resumed partially their normal activities (Prolo 3); 12 (41\%) did not resume their normal activities (Prolo 1 and 2). Pre-operative mean Rolland-Morris score was 11.2 (5-20); mean post-operative score was 7.4 (1-22). Oswestry mean pre-operative and post-operative scores were 28.5 and 18.6 , respectively. These data show that $73 \%$ of Group I patients were moderately disabled pre-operatively (Oswestry 21-40\%) and there was significant improvement post-operatively with $70 \%$ of patients presenting minimum or no disability (Oswestry 0-20\%).

Group II (PLIF) - The median Economic Prolo scale score pre-operatively was 3.1 (2-5) and post-operatively 4.1 (2-5). Twenty-five patients (83.3\%) returned to their baseline normal activities (Prolo grades 4 and 5). One patient (3.3\%) improved, but could not resume all his normal activities (Prolo grade 3 ). Four patients $(13.3 \%)$ did not return to their normal activities (Prolo grades 1 and 2). The pre-operative median Functional scale was 2.4 (1-5); post-operative 4.2 (25). Twenty-five patients $(83.3 \%)$ reported significant functional improvement, with no or sporadic back pain (Prolo 4 and 5). Partial functional recovery was observed in 4 patients (13.3\%), with back pain and residual pain in the lower extremities (Prolo grade 3). One patient $(3.3 \%)$ had no pain improvement (Prolo 1 and 2). Twenty-five patients resumed their normal activities post-operatively (Economic Prolo 4 and 5), and 25 patients reported significant functional recovery (Functional Prolo 4 and 5); 1 patient (3.3\%) resumed partially their normal activities (Prolo 3); 4 patients $(14.2 \%)$ did not resume their normal activities and 1 patient (3.3\%) showed no pain relief (Prolo 1 and 2). Pre-operative mean Rolland-Morris score was 9.5 (4-22); mean post-operative score was 3.7 (014), respectively. Pre-operative mean Oswestry score was $31.3 \%(16-80)$, and $13.3 \%(0-30)$ post-operative. These data show that $70 \%$ of Group II patients were moderately disabled pre-operatively (Oswestry 21$40 \%)$ and there was significant improvement postoperatively with $70 \%$ of patients presenting minimum or no disability (Oswestry $0-20 \%$ ).

In the present series 28 patients presented lowback pain pre-operatively with significant post-operative improvement in 18 patients (64\%). In Group II, all patients had low-back pain with significant improvement in 20 cases $(66.6 \%)$. Radicular pain was present in 28 patients with post-operative improvement in 23 cases ( $82 \%)$. In Group II, 28 patients presented radicular pain with post-operative improvement in 24 cases (85\%). Neurogenic claudication improved in all cases and in both Groups. Neurological deficits were present in 24 patients, 19 sensitive and 5 motor deficits (related to nerve roots L5 and S1). Group I had 2 patients with motor deficit, with one complete recovery (case 13) and one partial recovery (case 21). In Group II, 3 patients had motor deficit pre-operatively (cases $48,57,60$ ). There was full recovery in 2 cases, and partial in one case. Sensitive deficits were present in 12 cases with post-operative improvement in 8 patients (66\%). Group II had 7 cases with sensitive deficits in the pre-operative period with complete post-operative recovery in 5 cases $(71 \%)$.

Early and late surgical complications were studied. Early complications consisted of: nerve root compression caused by the hardware in 4 cases ( 2 on each group; surgical repositioning of the construct resolved back pain in all patients); superficial wound infection in 3 cases of Group II with 1 patient requiring surgical debridement (case 8); CSF leak in one patient in Group I, treated conservatively with bed rest. Late complications consisted of: 2 patients in Group I (cases 16 and 30 submitted to a 2 level- 6 screw fixation procedure) presented screw fractures with complaints of low-back pain, but not requiring re-opera- 
tion; loosening of the metal construct with slippage of the rods in two cases (cases 8 and 19, Group I) that complained of severe back pain and required re-operation, and partial displacement in one case (case 22, Group II) that was only followed radiologically; patient 27 of Group I presented with lumbar stenosis one level below fusion (performed at the L4-5 level), and was submitted to decompression and fusion at L5-S1 3 years after surgery.

From the biomechanical standpoint, Group I patients presented a higher complication rate with 2 screw fractures, 3 loosening of the construct, and 1 spinal stenosis below the fixated segment. No such complications occurred in Group II patients. This difference was statistically significant. The overall re-operation rate was $13.6 \%$ ( 8 cases), $6.6 \%$ in Group I ( 2 cases) and $20 \%$ in Group II (6 cases).

Difference between Groups I and II - There was no statistical significant difference in the overall results of the Oswestry and Rolland-Morris scales. Preoperative mean Rolland-Morris questionnaire score in Group I was 11.2 (5-20). The mean post-operative score was 7.4 (1-22). Oswestry's questionnaire mean score pre-operatively and post-operatively were $28.5 \%$ and $18.5 \%$, respectively. Pre-operative mean Rolland-Morris questionnaire score in Group II was 9.6 (4-22). The mean post-operative score was 3.7 (014). Oswestry's questionnaire mean score pre-operatively and post-operatively were $31.3 \%$ (16-80) and $13.3 \%$ (0-30), respectively. There was no significant statistical difference between the two groups when studied by the Economic and Functional Prolo Scale. However, analysis of patients E1F1 and E2F2 pre-operatively that improved to E4F4 and E5F5, showed that patients in Group II fared better than patients in Group I: Economic 50\% and 21\% for Groups II and I; and Functional $86 \%$ and $60 \%$ for Groups II and I.

\section{DISCUSSION}

The ideal surgical treatment for spondylolisthesis patients remains controversial. Moller ${ }^{21}$ reported a prospective randomized study with 111 patients with isthmic spondylolisthesis and with a follow-up of two years. Patients were submitted to conservative treatment or a postero-lateral surgical approach with or without placement of pedicle crews. They conclude that surgery provided better clinical outcomes and pain improvement. Gibson ${ }^{22}$ published a meta-analysis comparing the various methods of treatment of lumbar spondylolisthesis. The study concluded that there was no evidence that surgical decompression or fusion were superior than the natural history, placebo, or conservative management. Ape ${ }^{23}$ found high rates of pseudoarthrodis $(43 \%)$ in patients submitted to a simple posterior fusion procedure, without good clinical outcomes. Herkowitz and $\mathrm{Kurz}^{24}$ studied prospectively 50 patients with degenerative spondylolisthesis that were equally divided into two groups. Patients were submitted to isolated surgical decompression or decompression with postero-lateral fusion. Follow-up period was 3 years. Patients submitted to decompression and fusion presented better results than decompression alone $(96 \%$ vs. $44 \%)$. Pseudoarthrosis rate in the decompression alone group was $36 \%$, but it had no influence in clinical results.

Fishgrund ${ }^{25}$ published a prospective randomized study with three different groups of patients with degenerative spondylolisthesis, submitted to different surgeries: decompressive laminectomy, fusion without instrumentation, and fusion with instrumentation. Patients submitted to fusion and instrumentation presented better fusion rates, but it did not improve clinical outcome. Kornblum ${ }^{26}$ reviewed the study of Herkovitz and Kurtz ${ }^{24}$ and followed the patients for 7 years. They found the pseudoarthrosis rate influenced the final results. In patient with solid fusion, $86 \%$ presented good or excellent results, and the patients with pseudoarthrodis had only $56 \%$ of good or excellent results. The authors recommend then, the use of instrumentation with pedicle screws in patients submitted to fusion.

Yuan ${ }^{27}$, in a multicentric study with 2684 patients lumbar spondylolisthesis, compared 2177 patients submitted to fusion with pedicle screws with 507 patients submitted to decompression without pedicle screws. The complications of both procedures were analyzed. They noted $1 \%$ screw fracture. Per-operative dural tears were present in $7.3 \%$ of patients in the pedicle screws group, and in $5.7 \%$ in the decompression without fusion group. CSF fistula was found in $0.5 \%$ in the fusion group, and in $0.7 \%$ in the decompression group. Re-operation rate was $17.6 \%$, and $15 \%$, respectively, for the fusion with pedicle screw group, and decompression alone group. They conclude the benefits of pedicle screws over its risks.

In our series, no patient of Group II presented complications related to hardware biomechanics. Six patients of Group I presented complications: 3 patients presented with loosening of the construct, with rod slippage in 2 patients (cases 8 and 19) re- 
quiring re-operation. One patient presented with rod displacement (case 22), but did not require surgery. Two patients presented with screw fracture (cases 16 and 30), and another patient presented with late onset lumbar spine stenosis just above the fixated segment, requiring new surgery with decompression and fusion. The complications affected the final outcome, since only two of these 6 patients resumed their normal pre-operative activities and complained only sporadic back pain (Prolo E4F4). There was significant statistical difference in the complication rate of Group I when compared with Group II.

Madan ${ }^{16}$ compared 23 patients with lumbar spondylolisthesis submitted to a posterior fusion procedure with 21 patients submitted to a posterior fusion procedure and interbody fixation. Three patients in the first group lost surgical correction of the spondylolisthesis, while no patient in the second group presented such complication. However, the overall complication rate was not statistically significant between the two groups. Some authors consider the PLIF procedure difficult due to the increased bleeding, prolonged operation time, and more extensive dissection ${ }^{7,8}$. The reported complications associated with the PLIF procedure include: permanent neurological deficit in 0.4 to $1.7 \%$; CSF leak in 0.4 to $0.5 \%$; radicular pain in 1.1 to $2,5 \%$; posterior displacement of the cage in 0.8 to $0.9 \%$; deep wound infection in 0.6 to $5.0 \%{ }^{27-29}$.

In spondylolisthesis patients, concern with spinal biomechanics is key to the proper surgical management. This is in accordance with the literature. Intersomatic lumbar spacers along with posterior fusion are used with the purpose to improve fusion and spinal biomechanics, and provide a better support for the anterior spine column ${ }^{11,12}$. Duffield ${ }^{30}$ have demonstrated, in fatigue tests, the need for an anterior support for the lumbar spine. Posterior pedicle screws used alone tend to resist to the physiological forces applied to the anterior part of the vertebral body. Crawford and Cagli ${ }^{31}$ reproduced the lumbar spondylolisthesis grade I using cadaveric specimens, and studied the biomechanics of various hardware constructs: cages with and without intersomatic spacers; pedicle screws alone; pedicle screws with cages. Pedicle screws with cages presented better biomechanics in flexion, lateral extension, axial rotation, and shear forces. In specimens with cages, there were instability and fatigue. The authors suggest the use of screw systems and cages in grade I lumbar spondylolisthesis patients, because its high stability may allow for a good fusion around the cages.
Suk $^{12}$ compared two groups of patients with lumbar spondylolisthesis. Group I comprised 40 patients submitted to decompression and fusion with pedicle screws. Group II comprised 31 patients submitted to decompression, postero-lateral fusion, and a PLIF with the placement of discal space grafts. The pseudoarthrosis rate in Group I was $7.5 \%$ with $20 \%$ recurrence of deformity and lost of reduction in more than $50 \%$ of the cases. They recommend the posterior fusion associated with interbody grafting (PLIF), since anterior support presents lost of reduction achieved in surgery.

The literature shows concerns with life quality in spondylolisthesis patients. Madan ${ }^{16}$ used the Oswestry questionnaire, among other tools, to evaluate the final outcomes of patients with lumbar spondylolisthesis submitted to a posterior fusion procedure or to a PLIF procedure. Oswestry index of $69 \%$ was reported in the posterior fusion group, and a $81 \%$ index was reported in the PLIF group. PLIF patients retained correction and presented better fusion.

Our study shows Oswestry index with $90 \%$ good or excellent results in Group I patients, and $93 \%$ in Group II patients. The difference was not statistically significant.

La Rosa ${ }^{15}$ used the Prolo scale associated with other evaluation methods to compare 18 patients submitted to a posterior fusion surgery with $17 \mathrm{pa}$ tients submitted to a PLIF procedure. The pre-operative mean Economic Prolo scale in the first group was 2.5 (1-4). Twelve patients (66.7\%) presented good results (Prolo 4 and 5). The second group presented a mean pre-operative Economic Prolo scale 2.5 (1-4). Twelve patients $(70.6 \%)$ presented good results postoperatively (Prolo 4 and 5). The pre-operative mean Functional score was 4.2 (2-5). Post-operatively, 13 patients (76.5) presented good results pre-operative normal activities, pain relief was better in group two, but with no statistical significant difference.

Our study showed that Group I pre-operative mean Prolo Economic score was 2.4 (1-4). Thirteen patients $(43 \%)$ reported pain relief and resumed their normal activities. The pre-operative mean Prolo Functional score was 2.3 (1-5). Eighteen patients (60\%) reported significant improvement and sporadic pain (Prolo 4 and 5). Group II patients presented a pre-operative mean Prolo Economic score of 3.1 (2-5), and 27 patients (83.3\%) resumed their activities (Prolo 4 and 5). The pre-operative mean Prolo Functional score was 2.4 (1-5). Twenty-five patients (83.3\%) reported significant pain relief (Prolo 4 and 5). If we consider the 
subgroup of patients with a pre-operative Prolo E1F1 or E2F2 that improved to a Prolo E4F4 or E5F5 patients in Group II did better than patients in Group I: $50 \%$ vs. $21 \%$ (Economic); and $86 \%$ vs. $60 \%$ (Functional).

In conclusion, based on the present series we conclude that if there is instability affecting the three spine-columns, the posterior interbody fusions with pedicle screws provide a more solid mechanical construct when compared with the pedicle screws used alone. Both surgical procedures are effective, although Group II showed better clinical outcomes if quality of life, pain improvement, and functional recovery are considered. There were more complications related to spinal biomechanics in Group I than in Group II. Clinical and functional outcome in both groups were similar, and no significant statistical difference was found. Comparing the final results in both groups with the Prolo Economic and Functional scale there was significant statistical analysis in the subgroup of patients that were level E1F1 or E2F2 pre-operatively that improved to level E4F4 and E5F5 postoperatively, Group II presented better results than Group I.

\section{REFERENCES}

1. Herbinaux, G. Traite sur divers: accouchement laborieu et sur lês polipe de la matrice. Brussels: J.L. De Boubers, 1782.

2. Frymoyer JW, Selby DK. Segmental instability. Rational for treatment. Spine 1985;15:1216-1222.

3. Meyrding HW. Spondylolisthesis. Surg Gynecol Obstet 1932;54:371-377.

4. Roy-Camille R ,Demeulenaere C. Ostéosynthése du rachis dorsal, lombaire et lombo-sacré par plaques metalliqyes vissées dans les pedicules vertebraux et les apophyses articulaires. Presse Med 1970;78:1447-1450.

5. Zdeblick TA. A prospective, randomized study of lumbar fusion.Spine 1993;18:983-991.

6. Gill GG, Manning JG, White HL. Surgical treatment of spondylolisthesis without spine fusion. J Bone Joint Surg (Am) 1955;37:493-520.

7. Dai L Y,Jia L S, Yuan W, et al. Direct repair of defect in lumbar spondylolysis and mild isthmic spondylolisthesis by bone grafting, with or without joint fusion. Eur Spine J 2001;10:78-83.

8. Feffer HL, Wiesel SW, Cuckler JM, Rothman RH. Degenerative spondylolisthesis: to fuse or not to fuse. Spine 1985;10:287-289.

9. Briggs DS, Milligan PR. Chip fusion of the low back following exprolation of the spinal canal. J Bone Joint Surg (Am) 1944;26:125-130.

10. Cloward RB.The treatment of ruptured lumbar intervertebral disc by vertebral body fusion: indications, operative techinique, after care. J Neurosurg 1953;10:154-168.
11. Steffe AD, Sitkowski DJ. Posterior lumbar interbody fusions and plates. Clin Orthop 1988;227:99-102.

12. Suk S, Lee CK, kim W, Lee J, Cho K. Adding posterior lumbar interbody fusion to pedicle screw fixation and posterior fusion after decompression in spondillytic spondylolisthesis. Spine 1997;22:210-220.

13. Brantigan JW, Steffe AD, Quin LM, Persenaire JM.Lumbar interbody fusion using the Brating I/F cage for posterior lumbar interbody fusion and the variable pedicle screw system. Spine 200;25:1437-1446.

14. Ray CD.Threaded titanium interbody fusions. Spine 1997;22:667-679.

15. La Rosa G, Conti A, Cacciola F, et al. Pedicle screw fixation for isthmic spondylolisthesis: does posterior lumbar interbody fusion improve outcome over posterolateral fusion? J Neurosurg (Spine 2) 2003;99:1-15.

16. Madan S, Boeree NR.Outcome of posterior lumbar interbody fusions versus posterolateral fusion for spondylolisthesis.Spine 2002;27:15361542 .

17. Newman PH. Spondylolisthesis: its cause and effect. R Coll Surg England 1955;16:305-322.

18. Prolo DJ, Oklund SA, Buther M. Toward uniformity in evaluating results of lumbar spine operations: a paradigm applied to posterior interbody fusions. Spine 1986;22:601-606.

19. Rolland M, Morris R. A study of the natural history of low back pain. Part 1: Development of a reliable and sensitive measure of disability in low back pain. Spine 1983;8:141-144.

20. Fairbank J, Couper J, Davies J. The Oswestry low back pain questionaire. Physioterapy 1980;66:271-273.

21. Moller H, Hedelund R. Surgery versus conservative management in adult isthmic spondylolisthesis: a prospective randomized study. Part 1. Spine 2000;25:1711-1715.

22. Gibson JNA, Waddell G, Grant IC. Surgery for degenerative lumbar spondylosis (Cochrane Review ). In: The Cochrane Library Issue 2002; 1:1-24.

23. Apel DM, Lorenz MA, Zindrick MR. Symtomatic spondylolisthesis in adults fours decads later. Spine 1989;14:345-348.

24. Herkowitz BN, Kurz L. Degenerative lumbar spondylolistesis with spinal stenosis. J Bone Joint Surg 1991;73:802-808.

25. Fischgrund JS, Mackay M, Herkowitz HN, Brower R, Montgomery DM, Kurz LT. Volvo award vinner in clinical studies. Degenerative lumbar spondylolistesis with spinal stenosis: a prospective randomized study comparing descompressive laminectomy and arthrodesis with and without spinal instrumentation. Spine 1997;22:2807-2812.

26. Kornblum MB, Fischgrund JS, Herkowitz HN, Abrahan DA, Ditkopff JS. Degenerative lumbar spondylolisthesis with spinal stenosis: a prospective long-term study comparing fusion and pseudoatrtrhosis. Presented at the American Academy of Orthopedic Surgeons. Annual Meeting; Orlando, FL. 2000.

27. Yuan HA, Garfin SR, Dickman CA, Mardjetko SM. A historical cohort of pedicle screw fixation in thoracic, lumbar, and sacral spinal fusions. Spine 1994;19:2279-2296.

28. Davne SH, Myers DL. Complication of lumbar spinal fusion with transpedicular instrumentation. Spine 1992;17:184.

29. Lin PM. Posterior lumbar interbody fusion techinique: complication and pitfalls. Clin Orthop 1995;193:90-102.

30. Duffield RC, Carson WL, Chen CY. Longitudinal element size effect on load sharing, internal loads, and fatigue life of tri-level spinal implants constructs. Spine 1993;18:1695-1703.

31. Crawford S, Çagli S, Sontag VKH. Biomechanics of grade I degenerative lumbar spondylolisthesis: part 1. In vitro model. J Neurosurg (Spine 1) 2001;94:45-50. 